\title{
Preparing for liver surgery with "Alphabet Soup": PVE, ALPPS, TAE-PVE, LVD and RL
}

\author{
DaeHee Kim ${ }^{1}$, Joshua Cornman-Homonoff ${ }^{2}$, David C. Madoff ${ }^{2}$ \\ ${ }^{1}$ Department of Radiology, Division of Interventional Radiology, Memorial Sloan Kettering Cancer Center, New York, NY, USA; ${ }^{2}$ Department of \\ Radiology and Biomedical Imaging, Section of Interventional Radiology, Yale School of Medicine, New Haven, CT, USA \\ Contributions: (I) Conception and design: All authors; (II) Administrative support: DC Madoff; (III) Provision of study materials or patients: All \\ authors; (IV) Collection and assembly of data: All authors; (V) Data analysis and interpretation: All authors; (VI) Manuscript writing: All authors; (VII) \\ Final approval of manuscript: All authors. \\ Correspondence to: David C. Madoff, MD. Department of Radiology and Biomedical Imaging, Section of Interventional Radiology, Yale School of \\ Medicine, 330 Cedar Street, TE-2, New Haven, CT 06520, USA. Email: david.madoff@yale.edu.
}

\begin{abstract}
Future liver remnant (FLR) size and function is a critical limiting factor for treatment eligibility and postoperative prognosis when considering surgical hepatectomy. Pre-operative portal vein embolization (PVE) has been proven effective in modulating FLR and now widely accepted as a standard of care. However, PVE is not always effective due to potentially inadequate augmentation of the FLR as well as tumor progression while awaiting liver growth. These concerns have prompted exploration of alternative techniques: associating liver partition and portal vein ligation for staged hepatectomy (ALPPS), transarterial embolization-portal vein embolization (TAE-PVE), liver venous deprivation (LVD), and radiation lobectomy (RL). The article aims to review the principles and applications of PVE and these newer hepatic regenerative techniques.
\end{abstract}

Keywords: Hepatic regeneration; future liver remnant; embolization

Submitted Jul 30, 2019. Accepted for publication Sep 10, 2019.

doi: $10.21037 / \mathrm{hbsn} .2019 .09 .10$

View this article at: http://dx.doi.org/10.21037/hbsn.2019.09.10

\section{Introduction}

Extended hepatectomy with curative intent is widely utilized in patients with a variety of primary and secondary liver diseases. Recent advancements in surgical technique and peri-operative management have enabled more aggressive resection, leaving the size of the future liver remnant (FLR) as one of the most critical determinants of treatment eligibility and postoperative prognosis (1).

The prodigious regenerative capacity of the human liver is now well-established (2-5). In 1897, Sir James Cantlie first documented the concept of the atrophy-hypertrophy complex in autopsy observations made in a patient with injury to the right hepatic lobe $(2,6)$. Compensatory hypertrophy after bile duct or portal vein occlusion was demonstrated in animal experiments as early as the first half of $20^{\text {th }}$ century $(7,8)$. In 1986, Kinoshita et al. first described the possibility of broadening resection candidacy through compensatory liver enlargement achieved via portal vein embolization
(PVE), although the original intention was to treat portal tumor thrombi in the setting of hepatocellular carcinoma (9). Shortly thereafter in 1990, Makuuchi et al. reported the first series on PVE, performed in 14 patients with hilar cholangiocarcinoma, demonstrating the safety and feasibility of the technique in decreasing post-resection liver failure (10).

Pre-operative PVE is now accepted as standard of care for patients undergoing partial hepatectomy. However, the potential for inadequate augmentation of the FLR as well as tumor progression while awaiting liver growth have prompted exploration of alternative techniques. Newer strategies have recently been developed, chief among them associating liver partition and portal vein ligation for staged hepatectomy (ALPPS), transarterial embolizationportal vein embolization (TAE-PVE), liver venous deprivation (LVD), and radiation lobectomy (RL) (11-13). This article summarizes the principles and applications of these techniques by reviewing available observational and 
experimental data.

\section{Physiology of liver regeneration}

In the absence of an inciting event or injury, less than $0.01 \%$ of normal hepatocytes are actively dividing at any point $(2,3,14,15)$. Upon hepatic injury, however, there is a dramatic increase in hepatocyte proliferation, mediated by the release of multiple growth factors, which continues for about 14 days $(3,15)$. Because the regenerative process depends upon the proliferation of the remaining uninjured hepatocytes, the regenerative rate and capacity in chronically diseased livers is lower than that in healthy livers (16-19). Multiple changes within the portal venous system are thought to initiate the regenerative process. In the case of partial hepatectomy, resection results in a sudden increase in portal venous inflow within the remaining liver while the arterial supply remains unchanged $(15,20)$. Consequently, the liver experiences an increase in both portal venous pressure and delivery of intestinally-derived growth factors while simultaneously experiencing decreased oxygen delivery secondary to a relative increase in the ratio of portal venous to arterial blood supply $(2,3,14,15,18)$. The resulting alterations in endothelial stress, vascular permeability, growth factor delivery, and oxygen tension trigger a regenerative pathway which closely resembles that which occurs during the typical wound-healing process.

At the molecular level, numerous growth factors and signaling pathways are involved in hepatocyte activation and hyperplasia, as reflected by animal studies demonstrating upregulation of more than 100 genes within a few hours of hepatic resection $(21,22)$. The hepatocyte-specific mitogen hepatocyte growth factor (HGF) is stored in the extracellular matrix of the liver and is released upon tissue injury, resulting in a delayed genetic response $(3,15,21)$. Intestinally-derived trophic factors such as epidermal growth factor (EGF) are delivered to the injured liver in greater concentration secondary to augmented portal inflow, as previously described $(15,22,23)$. Finally, global trophic hormones such as insulin appear to play a synergistic role in hepatocyte stimulation as slower rates of FLR growth have been observed in diabetic patients $(16,24)$.

\section{Estimation of future liver remnant (FLR), kinetic growth rate (KGR) and quantitative liver function}

Accurate estimation of FLR size is critical when planning hepatectomy and establishing the need for preoperative hepatic augmentation. The FLR is typically measured on cross-sectional imaging, most commonly using computed tomography (CT) (Figure 1). Because liver volume directly correlates with body size (25), normalization of the FLR to total liver volume (TLV), termed standardized FLR (sFLR), has been suggested and clinically validated $(26,27)$. Total estimated liver volume (TELV) is calculated using the using the following formula: TELV $=-794.41+126.28 \times \mathrm{BSA}$ (where BSA is body surface area) $(26,27)$. This formula was derived utilizing data from 292 subjects obtained in four centers in North America and Europe and had been shown to be accurate in estimating the TLV (1,26-28). Alternatively, the TLV can be calculated using CT volumetry, but this technique adds empirical measurement errors and tends to over-estimate FLR size due to a degree of liver atrophy which occurs as a result of pre-operative regenerative interventions (29).

The FLR volume required for safe liver resection varies with the underlying liver health. An FLR greater than $20 \%$ is generally considered safe for hepatectomy in patients without liver disease (27,30-32). In liver injured by chemotherapy, steatosis, infection, or other iatrogenic injury, a threshold of $30 \%$ is recommended to minimize the risk of post-operative liver failure (33-36). In patients with severe liver disease, including those with cirrhosis, a minimum of $40 \%$ is desired $(1,33,34)$.

$\mathrm{KGR}$ is an alternative predictor of post-resection liver failure following PVE (37). It refers to hypertrophy per time after PVE and has been shown to better predict both post-resection liver insufficiency and mortality as compared to sFLR. In a study of 107 subjects undergoing right hepatic PVE and subsequent hepatectomy, Shindoh et al. reported no liver failure or deaths in the 68 patients with KGR greater than $2 \%$ per week (37).

Clearance of indocyanine green (ICG) has been used as a biochemical surrogate for global quantitative liver function and shown to be predictive of outcomes when utilized in conjunction with FLR, particularly in patients with cirrhosis (38-40). More recently, technetium-99m-mebrofenin hepatobiliary scintigraphy (HBS) (41-43) and technetium$99 \mathrm{~m}$-diethylenetriaminepentaacetic acid-galactosyl human serum albumin single photon emission computed tomography (GSA SPECT) $(41,44,45)$ were introduced and utilized in order to accurately account for heterogeneous hepatic functionality in case of prior insults or intervention to the part of the liver, for example, portal tumor thrombus or regional biliary obstruction. Lastly, the liver function estimate based on magnetic resonance imaging (MRI) with 

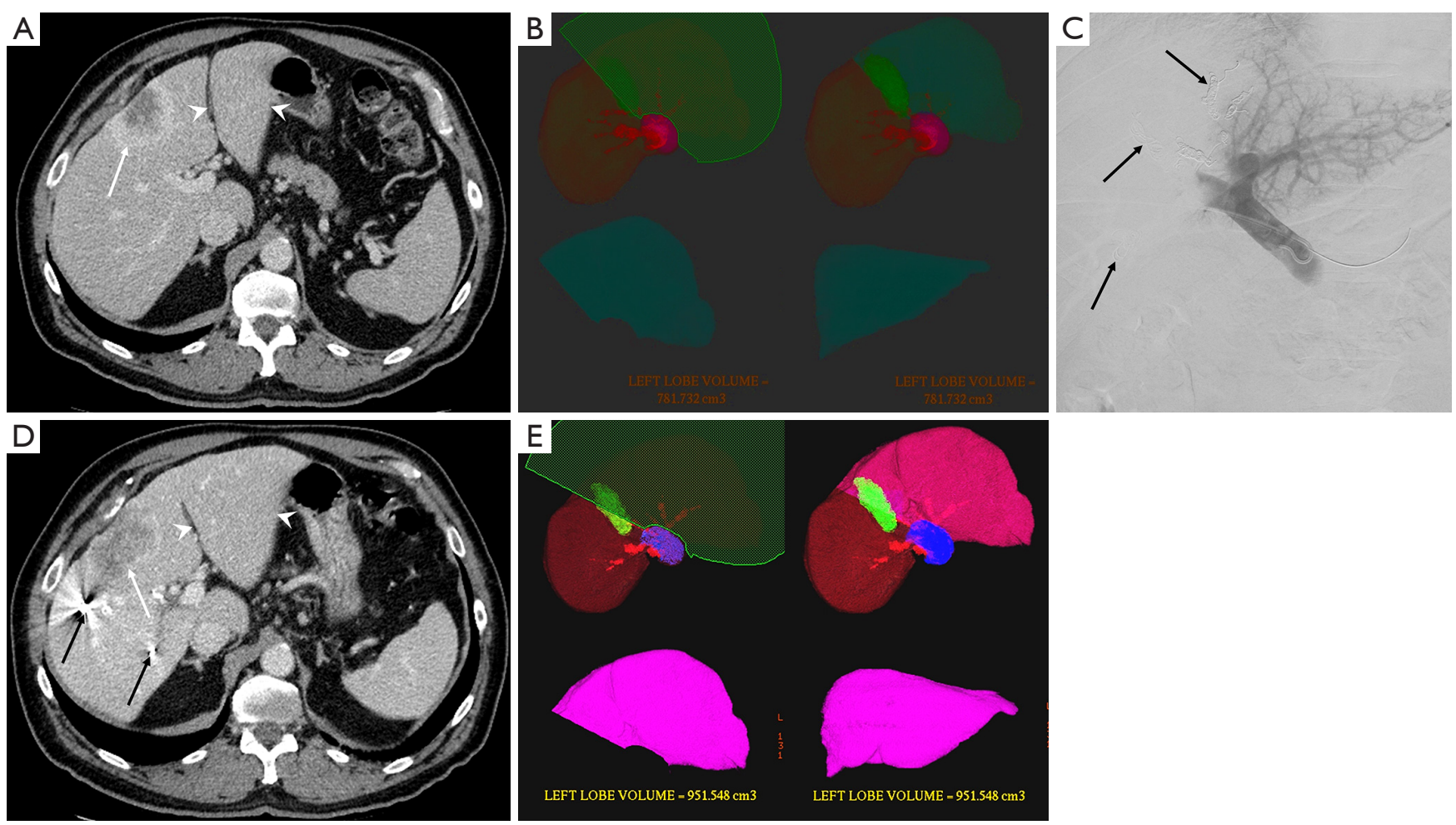

Figure 1 A 71-year-old man with intrahepatic cholangiocarcinoma who underwent right portal vein embolization (PVE) for small projected future liver remnant (FLR). (A) Pre-procedural contrast-enhanced CT showing the tumor (arrow) and left hepatic lobe (arrowheads); (B) pre-procedural 3D CT volumetry demonstrating segmentation (upper left) and isolation (upper right) of the left hepatic lobe with analysis of volumes (bottom left and right); (C) patient underwent right hepatic PVE with coils (arrows); (D) post-procedural contrast-enhance CT showing the tumor (white arrow), coils (black arrows), and hypertrophy of the left hepatic lobe (arrowheads); (E) post-procedural 3D CT volumetry confirms increase in left hepatic lobe volume.

Gadolinium ethoxybenzyl diethylenetriamine pentaacetic acid (Gd-EOB-DTPA) demonstrates promising results with on-going investigation (46-48).

\section{PVE}

PVE is the mainstay of preoperative liver augmentation and substantial data confirming its safety and efficacy have accrued since it was first performed over 30 years ago. The procedure is indicated when the expected FLR is too small to provide adequate function. It is performed on the tumorbearing liver to promote hypertrophy of the unaffected lobe, and is most effective when there is complete occlusion of the treated portal veins without the opportunity for recanalization or collateral formation (49) (Figure 2).

Access to the portal system is typically obtained via percutaneous transhepatic puncture. Either ipsilateral or contralateral approaches may be taken (in reference to the segment of tumor-bearing liver), with arguments in favor of each. The ipsilateral approach minimizes the risk of inadvertent injury to the FLR during PVE and provides easier access to the segment 4 portal veins if an extended right hepatectomy is planned $(50,51)$ (Figures 3,4). However, as embolic material is administered in a retrograde manner, care in catheter manipulation is essential once embolization has begun so as to prevent disruption of embolic material and consequent non-target embolization. Use of reverse curve and balloon occlusion catheters as well as placement of coils or plugs has been described for this approach (50-52). The contralateral approach has the advantages of facilitating cannulation and antegrade embolization of right portal vein branches, although iatrogenic injury to the FLR and difficult segment 4 access remain concerns. Thus far, comparisons between the two techniques have demonstrated equivalent efficacy and complication rates (32,50,52-54). As such, selection is usually dictated by operator preference and the need for treatment of segment 4 .

A variety of embolic materials have been utilized, 

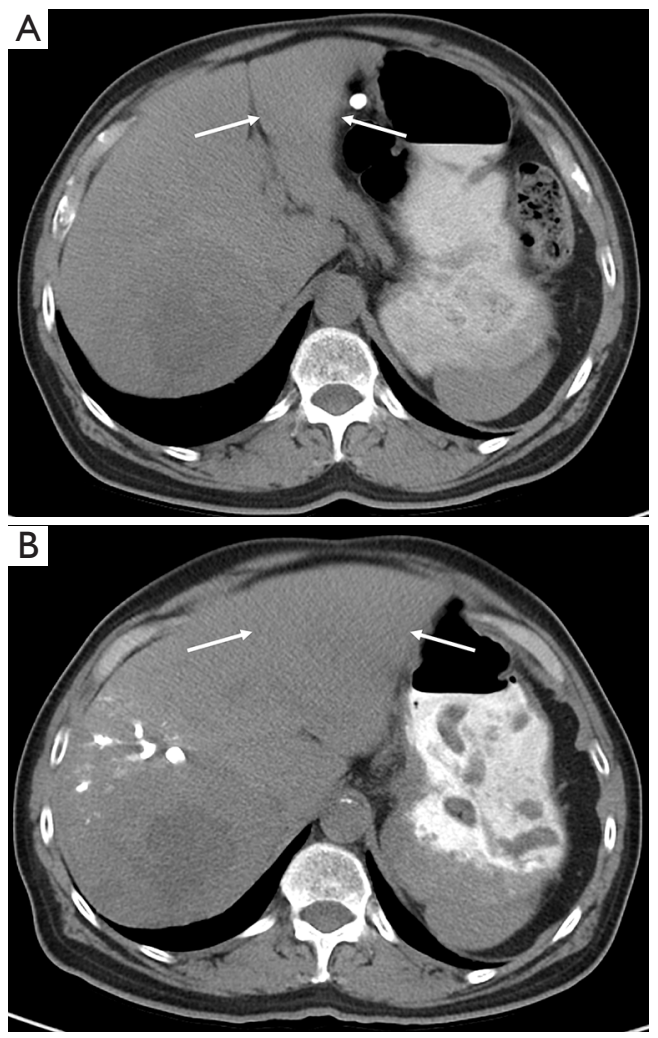

Figure 2 A 54-year old man with hepatocellular carcinoma who underwent right portal vein embolization (PVE) with lipiodol for small projected future liver remnant (FLR). Pre- (A) and post(B) embolization CT scans demonstrate significant increase in the volume of the left hepatic lobe (between arrowheads).

including polyvinyl alcohol (PVA), ethanol, microspheres, polidocanol, fibrin glue, lipiodol, and N-butyl-2cyanoacetate (NBCA), as well as coils and plugs (51,55-58). Among these, NBCA and the combination of coils and particles are the most widely used. The combination of coils and particles has been shown to be safe and effective in ensuring both proximal and distal embolization but at the expense of higher cost than when other materials are used (58). NBCA is both highly effective and substantially cheaper, but induces a peri-portal inflammatory reaction which can result in both a post-embolization syndrome and periportal fibrosis (55-58). Additionally, proficient use of NBCA can be challenging for the inexperienced interventionalist.

Reported technical success rates consistently reach greater than $95 \%$ regardless of the approach taken or embolic used (9,10,32,51,53,56-60) (Table 1). In the most recent systematic reviews and metanalyses, mean FLR hypertrophy rates were reported to be $37.9-49.4 \%$ and
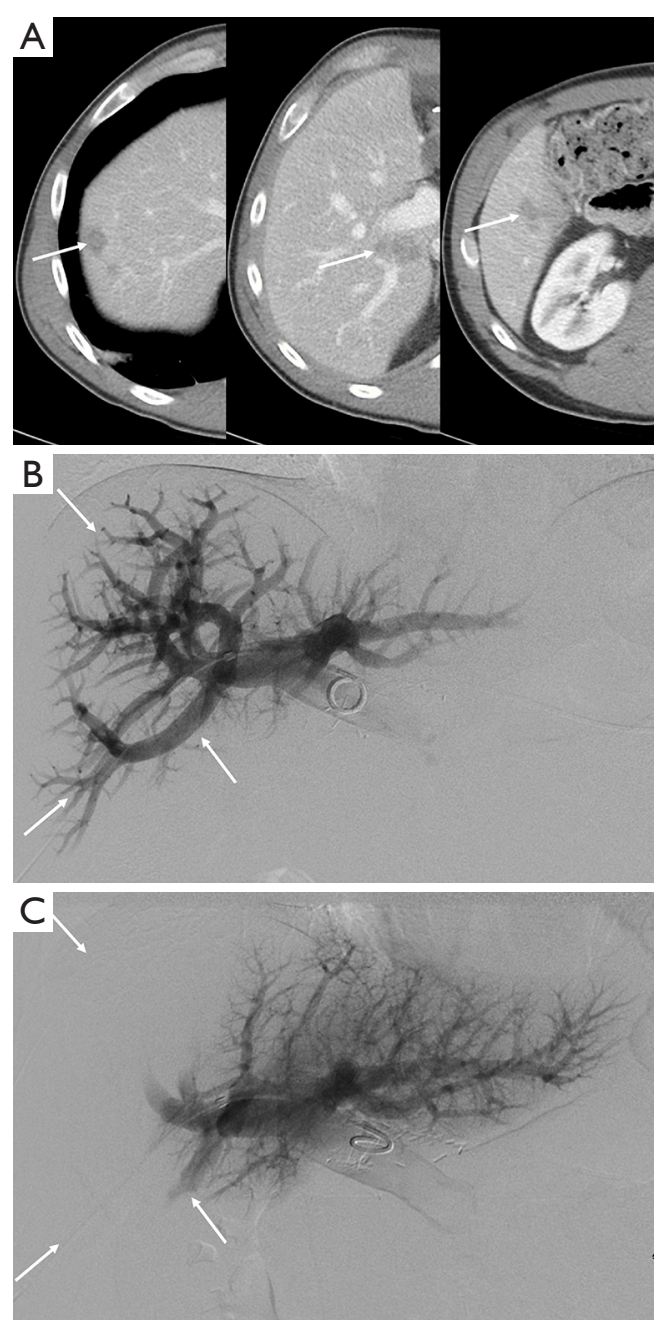

Figure 3 A 46-year-old man with metastatic colon cancer status post multiple hepatic wedge resections and hepatic arterial infusion pump placement, now planned for right hepatectomy and referred for pre-operative portal vein embolization due to small projected future liver remnant (FLR). (A) Pre-procedural contrast-enhanced CT showing multifocal tumor (arrows) in the right hepatic lobe; (B) digital substraction angiogram (DSA) demonstrating the preembolization appearance of the portal tree (arrows); (C) postembolization DSA showing absence of filling in the right side of the portal tree (arrows).

rates of successful hepatectomy were 75.9-96.1\% $(59,61,62)$. Major complications occur in $2.2-3.1 \%$ of cases, and mortality is less than $0.1 \%(59,61,62)$ (Table 1$)$.

The most commonly cited limitation to PVE is the potential for disease progression in the interval between embolization and resection. Some authors hypothesize that, in addition to the baseline rate of tumor growth, 

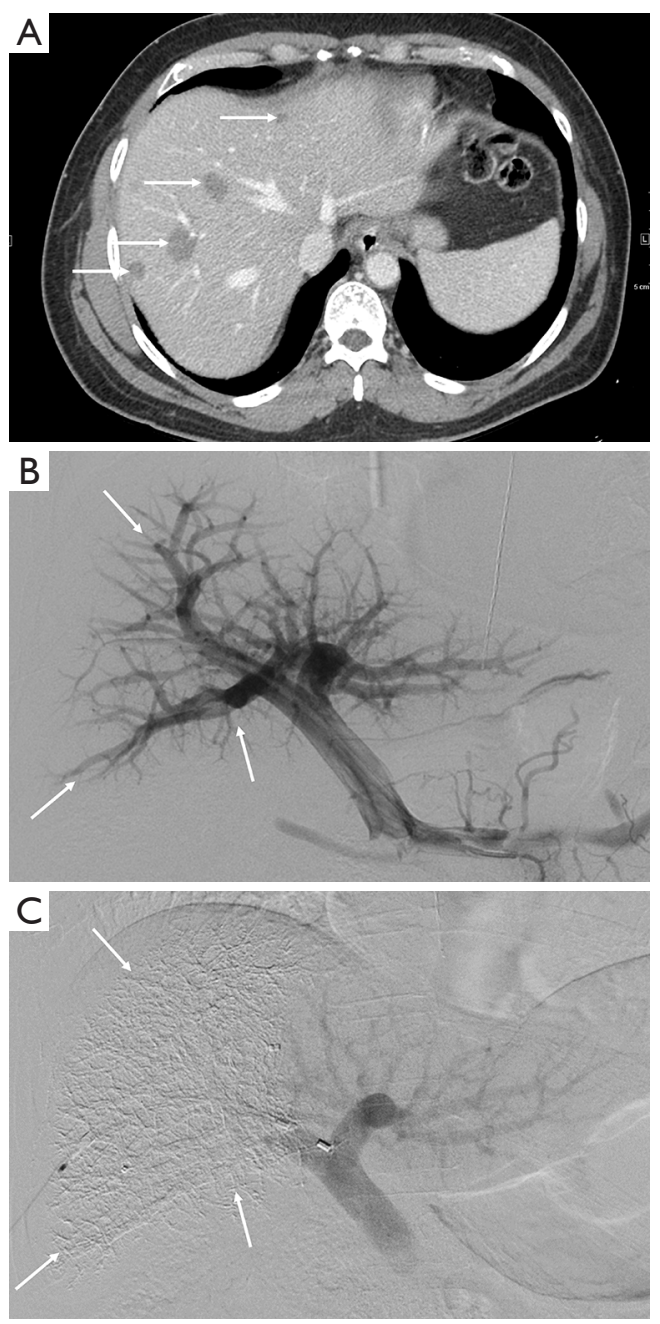

Figure 4 A 63-year-old man with metastatic colon cancer, planned for right hepatectomy and referred for pre-operative portal vein embolization due to small projected future liver remnant (FLR). (A) Pre-procedural contrast-enhanced CT showing multifocal tumor in the right hepatic lobe (arrows); (B) DSA demonstrating the preembolization appearance of the portal tree (arrows); (C) After embolization with lipiodol, DSA confirms absence of filling in the right side of the portal tree (arrows).

accelerated tumor progression may occur as a result of trophic factor release following PVE $(63,64)$. Several of the newer strategies described below are designed to prevent this progression by accelerating the rate of hypertrophy, controlling existing tumor, or both.

\section{ALPPS}

ALPPS is a surgical technique for FLR augmentation which was first described in 2012 (65). It consists of concurrent surgical portal vein ligation (PVL) and in-situ separation of the tumor-bearing liver from the FLR prior to eventual resection. Like PVE, the procedure induces FLR growth via deprivation of portal supply to the tumor-bearing liver, but it was hoped that it would produce more rapid and extensive FLR augmentation through more complete portal occlusion as well as elimination of collateral portal flow from the FLR into the diseased segment.

The initial description of the procedure performed in 25 patients by Schnitzbauer et al. demonstrated markedly accelerated mean FLR hypertrophy rates of $75 \%$ within a median of 9 days, albeit with high associated mortality and morbidity (12\% and $44 \%$, respectively) (65). Subsequent studies and meta-analyses have consistently demonstrated FLR hypertrophy rates of $68-80 \%$ within 7 days (66-68) (Table 2). A recent meta-analysis comprising a total of 657 subjects with colorectal liver metastasis (CRLM) found a significantly greater KGR compared to isolated PVE/PVL (mean difference $19.07 \mathrm{~mL} /$ day), although there was no significant difference in the ultimate size of the FLR (71). A randomized controlled trial performed in 97 patients with CRLM reported significantly higher rates of successful resection in patients who had undergone ALPPS compared with PVE/PVL (92\% vs. 57\%); in fact, 12 of the 13 PVE/ PVL patients who achieved insufficient FLR growth were subsequently successfully treated by ALPPS (67).

The main limitation to the technique is its substantial associated morbidity and mortality. Although decreased when compared to earlier studies $(65,69,70)$, the 90 -day mortality rate remains $8-9 \%(66,67)$ and both mortality and morbidity are elevated in comparison with PVE $(68,71)$. These findings were initially attributed to the increased invasiveness of the procedure and consequent bile leakage, which complicated $20 \%$ of the cases reported by Schnitzbauer et al. (65). However, subsequent analysis of 320 subjects registered an international ALPPS database revealed that $75 \%$ of 90 -day mortality was in fact due to post-stage 1 liver failure, despite $82 \%$ of patients achieving the goal FLR $(66,72)$. This finding prompted consideration of volumefunction dissociation as a potential cause for the liver failure, and further emphasized the importance of liver function analysis before performance of stage 2 resection $(73,74)$. Histologic analysis of the post-ALPPS FLR demonstrated immaturity of both hepatocytes and the supporting stroma, which was not observed to comparable extent in the postPVE FLR $(75,76)$. In light of these findings, several modified versions of ALPPS have been proposed in an attempt to 
Table 1 Summary of meta-analysis and systematic reviews on PVE

\begin{tabular}{|c|c|c|c|c|c|c|c|c|}
\hline Author, year & Type & $\begin{array}{l}\text { \# included } \\
\text { studies/ } \\
\text { patients }\end{array}$ & $\begin{array}{l}\text { Morbidity/ } \\
\text { mortality } \\
\text { of PVE (\%) }\end{array}$ & $\begin{array}{c}\text { FLR } \\
\text { increase } \\
(\%)\end{array}$ & $\begin{array}{l}\text { Rates of } \\
\text { successful } \\
\text { resection } \\
\text { (\%) }\end{array}$ & $\begin{array}{c}\text { Morbidity/ } \\
\text { mortality } \\
\text { post-resection } \\
\text { (\%) }\end{array}$ & $\begin{array}{l}\text { Difference between } \\
\text { ipsilateral/contralateral } \\
\text { transhepatic approach }\end{array}$ & $\begin{array}{c}\text { Difference } \\
\text { between the } \\
\text { choice of embolic }\end{array}$ \\
\hline $\begin{array}{l}\text { Abulkhir et al., } \\
2008 \text { (59) }\end{array}$ & Meta-analysis & $37 / 1,088$ & $2.2 / 0$ & 8-27 (DH) & 85 & $16 / 1.7$ & None & None \\
\hline $\begin{array}{l}\text { Isofordink } \\
\text { et al., } 2017 \text { (61) }\end{array}$ & $\begin{array}{l}\text { Meta-analysis } \\
\text { and Systematic } \\
\text { Review }\end{array}$ & $17 / 1,953$ & $\begin{array}{c}3.9 / \text { not } \\
\text { reported }\end{array}$ & $43.2(\mathrm{RH})$ & $\begin{array}{l}\text { Not report- } \\
\quad \text { ed }\end{array}$ & $\begin{array}{c}\text { Not } \\
\text { reported/3.8 }\end{array}$ & Not reported & Not reported \\
\hline $\begin{array}{l}\text { van Lienden } \\
\text { et al., } 2013 \text { (62) }\end{array}$ & $\begin{array}{l}\text { Meta-analysis } \\
\text { and Systematic } \\
\text { Review }\end{array}$ & $44 / 1,791$ & $2.5 / 0.1$ & $37.9(\mathrm{RH})$ & 80 & $10.4 / 3.3$ & Not reported & $\begin{array}{c}\text { NBCA with greater } \\
\text { FLR increase than } \\
\text { gelfoam, PVA and } \\
\text { fibrin glue }\end{array}$ \\
\hline
\end{tabular}

PVE, portal vein embolization; FLR, future liver remnant; $\mathrm{DH}$, degree of hypertrophy; $\mathrm{RH}$, relative hypertrophy; NBCA, N-butyl cyanoacrylate; PVA, polyvinyl alcohol.

Table 2 Summary of meta-analysis and systematic reviews on ALPPS

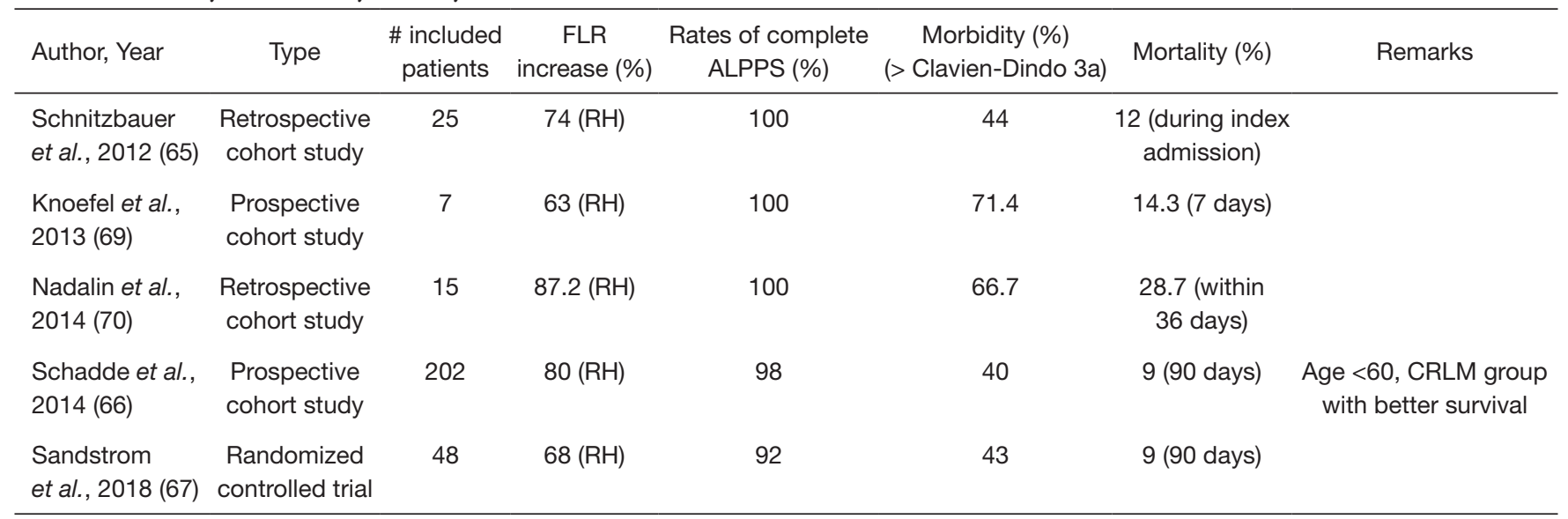

ALPPS, associating liver partition and portal vein ligation for staged hepatectomy; FLR, future liver remnant; $\mathrm{RH}$, relative hypertrophy; CRLM, colorectal liver metastasis.

improve outcomes. These alternatives usually employ a different method for the initial hepatic transection, for example through tourniquet application or radiofrequency ablation, but thus far their success remains unproven (66,74,77-81). Lengthening the interval between stage 1 and 2 to allow time for FLR maturation has also been suggested, but at least partially mitigates against the benefits provided by the increased KGR (71).

Given the associated morbidity and mortality of the technique, ALPPS is currently reserved for situations in which the risk-benefit ratio justifies its potential dangers $(82,83)$.

\section{Combination treatment of the portal vein and hepatic artery}

Although PVE reliably produces FLR hypertrophy in patients with otherwise healthy livers, the response is more variable in those with underlying liver disease. This prompted efforts to further augment FLR hypertrophy, 
with one approach focusing on added hepatic artery embolization (transarterial embolization, or TAE). Because the degree of FLR hypertrophy correlates directly with the extent of ischemia (84), it has been postulated that increasing ischemic severity via addition of TAE would produce more rapid and extensive FLR growth. This effect is likely to be further augmented via both obliteration of intrahepatic arterioportal shunts, which are common in diseased and tumor-bearing livers, and elimination of compensatory increases in arterial inflow, which can occur after PVE and is termed the hepatic arterial buffer response $(85,86)$. Additionally, TAE provides a strong anti-tumor effect, which may help to counteract the stimulatory effect on tumor growth observed following PVE and help to limit tumor progression in the interval between embolization and resection (9,86-93). The main theoretical limitation to this technique is the potential for ischemic necrosis of the noncancerous hepatic parenchyma, which has led to the adoption of an interval of days to weeks between performance of the two procedures $(84,90,91)$.

Sequential TAE+PVE has been evaluated in numerous small studies using variable order of and intervals between the two treatments. The most common approach utilizes TAE followed by PVE, although Gruttadauria et al. performed PVE first, reserving TAE for patients in whom sufficient hypertrophy was not initially achieved $(85,94)$. This latter approach has the appeal of potentially sparing patients who achieve sufficient post-PVE hypertrophy the need for a second intervention with its associated risks and surgical delay. Most series suggest that combination therapy does produce a more pronounced effect on FLR hypertrophy when compared with isolated PVE (39,84,86,91,94-96). For example, Ogata et al. and Vilgrain et al. both independently reported a $12 \%$ increase in FLR size for TAE+PVE compared with $8 \%$ for isolated PVE (although only the former reported a $\mathrm{P}$ value, which confirmed statistical significance at $\mathrm{P}=0.022)(91,96)$, while Yoo et al. reported increases of $7.3 \%$ and $5.8 \%$ for TAE+PVE and isolated PVE $(\mathrm{P}=0.035)$, respectively (95). In a series of 7 patients, Gruttadauria et al. described mean hypertrophy of $14.75 \%$ after initial PVE which then increased to $46.8 \%$ following TAE 6 weeks later (P value not reported), although most patients in this series were without underlying liver disease (94). This greater degree of hypertrophy translated to positive post-operative outcomes, with Ogata et al., Vilgrain et al., and Yoo et al. all reporting significantly increased disease-free survival following TAE + PVE, and the latter further reported significantly increased overall survival, findings which the authors attributed to reduced early recurrence resulting from increased tumor necrosis and decreased dissemination $(91,95)$. Of note, in the largest and only multicenter series available, Peng et al. found no significant difference in rates of FLR hypertrophy between PVE and TAE + PVE (97). However, the authors concluded that the procedure is safe and effective for simultaneous induction of FLR hypertrophy and treatment of intrahepatic disease while awaiting resection.

Initial concerns regarding hepatic parenchymal necrosis were ultimately not borne out. Although treatment is generally accompanied by a prominent transaminitis with the peak dependent in part upon the interval between the two interventions, levels typically normalize by the time of surgery without clinical consequence $(39,84,90,91,95,96,98)$. Pathologic evaluation of resection specimens has shown overall minimal necrosis of the noncancerous parenchyma, in contrast to the substantial tumor necrosis which occurs $(84,86,90)$. In fact, the differential effect on tumorbearing liver has prompted several authors to propose that combination TAE + PVE may be sufficient therapy in its own right if inadequate hypertrophy precludes resection $(89,91,96)$. Additionally, it has been shown that should resection not be performed, it is safe to perform post-PVE TAE $(99,100)$. Of note, several cases of hepatic abscess formation and/or sepsis were reported in patients who had undergone prior biliary intervention, suggesting particular care should be taken when evaluating these patients for TAE + PVE $(94,98,101)$.

\section{$L V D$}

A modification to the TAE+PVE technique, spurred by initial concerns regarding excessive hepatic ischemia and consequent infectious complications, involves embolization of the portal and hepatic veins, termed LVD (102) (Figure 5). In theory, this technique induces a degree of hepatic ischemia intermediate to PVE and TAE + PVE. By occluding hepatic venous outflow, any residual portal vein inflow is further reduced and hepatic artery inflow, while not eliminated, is decreased, helping to mitigate the hepatic arterial buffer response. Embolization of the right hepatic vein (RHV), for example, produces outflow obstruction in the right posterior and, to a lesser extent, anterior segments, ultimately affecting two-thirds of the right hepatic lobe volume $(102,103)$. An auxiliary benefit of this technique is the potential for pre-operative stimulation of venous collateral development (104). Because hepatic congestion 

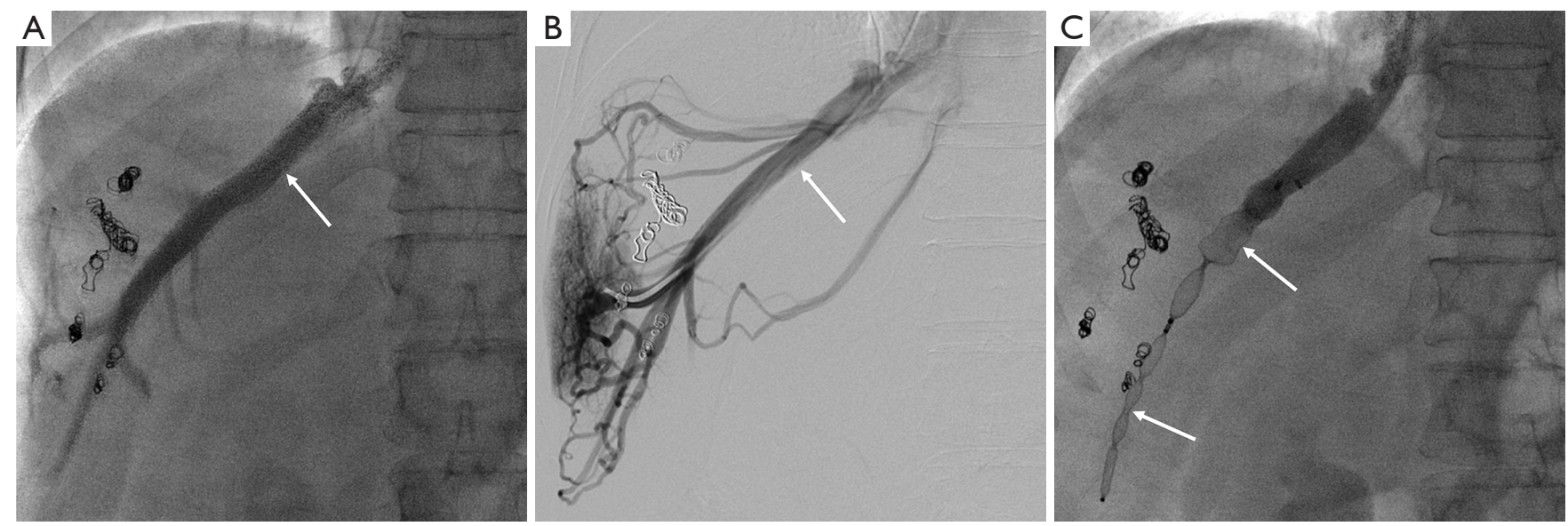

Figure 5 A 66-year-old woman with metastatic breast cancer, planned for right hepatectomy and referred for pre-operative portal vein embolization (PVE) due to small projected future liver remnant (FLR). Patient underwent prior PVE embolization with inadequate hypertrophy of the FLR, so embolization of the hepatic vein was undertaken. Angiogram (A) and DSA (B) showing the pre-embolization appearance of the right hepatic vein (arrow). (C) After embolization with multiple Amplatzer plugs, flow within the right hepatic vein is occluded (arrow).

resulting from outflow impairment has been shown to limit hepatic regeneration, the stimulation of venous collateral development before surgery may help to limit postoperative congestion that might otherwise contribute to graft failure (104-106).

Although initially reported as a sequential technique in which PVE was performed first followed by HVE several weeks later $(101,102)$, concurrent PVE and HVE has been shown to be feasible, safe, and effective (12). Likewise, while early reports used a transvenous approach, Guiu $\mathrm{et} \mathrm{al}$. described a trans-hepatic approach which they favored for its ease of performance and ability to embolize immediatelydeveloping veno-venous collaterals (12) (Figure 5B). In brief, the procedure is performed by advancing two sheathes into the liver via a transhepatic approach, one into the target hepatic vein and the other into a right portal vein branch. PVE is performed in standard fashion, while HVE is performed by first placing a vascular plug in the proximal hepatic vein to prevent migration of embolization material and then injecting a 1:1 mixture of lipiodol:nbutyl-cyanoacrylate upstream (12). The middle hepatic vein (MHV) can be embolized in addition to the RHV, which is termed extended liver venous deprivation (eLVD) (107). Of note, initial attempts by Hwang et al. to place an IVC filter and embolize with coils were complicated by migration of both, so the approach was abandoned $(101,102)$.

Although preliminary, initial results have thus far been promising $(12,101,102,108)$. In 12 patients who underwent sequential PVE and RHV embolization, Hwang et al. reported an increase in FLR from $34.8 \%$ before PVE to $39.7 \%$ 1-2 weeks after PVE to $44.2 \% 2$ weeks after HVE (102). Similarly, following concurrent PVE and HVE, Guiu et al. reported an increase from $28.2 \%$ to $40.9 \%$, although the series of 7 patients did not include any with cirrhosis or a control group who underwent isolated PVE (12). In a subsequent study directly comparing PVE and LVD in 12 patients with Klatskin tumor, FLR hypertrophy (using standardized FLR ratio) was significantly greater following LVD than PVE (58\% vs. 37\%, respectively; $\mathrm{P}=0.017$ ), and there was a trend towards shorter median postoperative hospital stay and 90-day mortality (109).

For eLVD, which involves embolization of the entire right hepatic venous outflow, results appear even more dramatic: FLR volume increased from $20.8 \%$ to $33.4 \%$ (standardized FLR ratio), KGR was 25 cc/day compared to $4.4 \mathrm{cc} /$ day after PVE and $9.3 \mathrm{cc} /$ day after LVD, and FLR function increased by $64.3 \%$ (107). Although transaminases peaked and then returned to baseline in a manner analogous to TAE + PVE, no complications related to hepatic necrosis occurred $(12,101,102,107)$. Although ALPPS produces comparable FLR hypertrophy to eLVD, the functional increase as measured by ${ }^{99 \mathrm{~m}} \mathrm{Tc}-$ mebrofenin hepatobiliary scintigraphy is substantially less (65.7\% for eLVD vs. 28.2\% for ALPPS), potentially explaining the high morbidity and mortality that accompanies the surgical procedure $(110,111)$. 


\section{$R L$}

$\mathrm{RL}$ is yet another alternative to PVE and its myriad variants for inducing FLR hypertrophy. The potential utility of this technique was first appreciated during analysis of the effects of radioembolization on the liver, where lobar treatment was noted to produce atrophy of the ipsilateral lobe and hypertrophy of the contralateral lobe (13,112-114). Principally, the technique is very similar to standard transarterial radioembolization in which yttrium-90 $\left({ }^{90} \mathrm{Y}\right)$ labeled microspheres are administered into the arteries supplying the tumor-bearing liver. However, it differs from the standard therapeutic approach in necessitating more proximal administration from a lobar artery as opposed to a segmental or subsegmental vessel, as well as utilization of higher overall radiation dose (115). This results in treatment not just of the tumor itself but of the ipsilateral non-tumorous hepatic parenchyma as well. Microvascular ischemia and high-dose brachytherapy result in hepatocyte injury and death, acting as locoregional treatment of the hepatic malignancy with simultaneous induction of FLR hypertrophy. Because of this, RL can be utilized either as a primary treatment in its own right or as a bridge to surgical resection (115). Although it shares the advantage of added tumor treatment with TAE + PVE, RL provides the benefit of being purely trans-arterial in nature without a transhepatic or portal venous component, thus allowing for single session treatment and facilitating intervention in the presence of portal vein thrombosis. In fact, portal vein thrombosis has been shown to be associated with increased degrees of FLR hypertrophy following RL, possibly as a result of functioning as a "natural PVE" (116).

Although most series report the effectiveness of RL for both tumor treatment and induction of FLR hypertrophy, only the latter is discussed here to place it in the context of as other regenerative modalities. Since its initial description in 2009, multiple series have demonstrated its efficacy albeit with wide variance in administered dosage, method of delivery (glass versus resin microspheres), number of sessions, treated pathology, underlying liver function, outcome assessment, and length of follow-up (Table 3). In 2014, Teo et al. performed a systematic review of these series (117) which included seven studies comprising 312 patients, of which the majority had HCC (69\%) and underwent treatment of the right lobe (91\%) (116,118-123). After noting the aforementioned data heterogeneity, the authors reported that the overall degree of FLR hypertrophy ranged between $26 \%$ and $47 \%$ at 44 days to 9 months. Included within this review was a direct comparison between RL and PVE, which found a significantly greater degree of hypertrophy with PVE (PVE 61.5\%, RL 29.0\%) within a shorter median time frame (PVE 33 days, RL 46 days) (122). Additionally, Vouche et al. and Fernandez-Ros et al. concluded that the post-embolization KGR is slower than that achieved with other therapies $(116,121)$. Consequently, evaluation of the extent of hypertrophic response should not occur before 3 months post embolization and, if not sufficient at that time, again at the 6-month timepoint (124).

Although there have been multiple attempts to identify factors associated with the degree of post-embolization hypertrophy, findings thus far have been inconsistent. Vouche et al., for example, identified the presence of portal vein thrombosis as the only predictor of increased FLR, whereas Goebel et al. found younger patient age, absence of portal hypertension (normal spleen size, platelet count $\geq 100 / \mathrm{nL}$, absence of ascites), absence of advanced liver disease (low Child Pugh score), and low tumor burden to each be independently associated with increased KGR $(116,125)$. Teo et al. described substantially greater hypertrophy in patients with underlying hepatitis B versus those with hepatitis $\mathrm{C}$ or alcoholic cirrhosis $(44.5 \%$ vs. $7.7 \%$ respectively; $\mathrm{P}=0.050$ ), a finding which the authors attributed to the health of the liver parenchyma (123). Palard et al. found that a mean hypertrophy rate of $>10 \%$ was associated with a dose to the healthy liver parenchyma of $\geq 88 \mathrm{~Gy}$, and/or to tumor of $\geq 205$ Gy when tumor volume is $\geq 100 \mathrm{~cm}^{3}$ (124).

$\mathrm{RL}$ is in general well-tolerated, with adverse events common to those seen in standard radioembolization (pain, flu-like symptoms, nontarget embolization) and typically transient, easily managed, or avoidable with good technique (116). Multiple studies have reported postembolization imaging findings suggestive of developing portal hypertension without clinical consequence $(112,121,123)$, and Vouche et al. described transient worsening of Child-Pugh scores which subsequently returned to baseline (116). Although surgical resection is performed much less commonly following RL than after other hypertrophic techniques secondary to use as destination therapy, preliminary reporting of surgical outcomes is promising. In a series of 13 patients undergoing RL followed by resection, Lewandowski et al. reported low post-operative morbidity, no mortality, and only one case of liver insufficiency, the latter secondary to a primary sclerosing cholangitis flare; after a median follow-up of 604 days, only one death had occurred (126). A subsequent 
Table 3 Summary of pertinent series on radiation lobectomy

\begin{tabular}{|c|c|c|c|c|c|c|c|c|c|}
\hline Author & Date & Patients & Tumor types & $\begin{array}{c}\text { Embolization } \\
\text { agent }\end{array}$ & $\begin{array}{l}\text { Treated } \\
\text { lobe }\end{array}$ & Dose & $\begin{array}{l}\text { \# Treatment } \\
\text { sessions }\end{array}$ & Follow-up & $\begin{array}{c}\text { Degree } \\
\text { hypertrophy }\end{array}$ \\
\hline $\begin{array}{l}\text { Jakobs } \\
\text { (overlap w/Vouche) }\end{array}$ & 2008 & 10 & $\begin{array}{c}\text { Mixed } \\
\text { metastases }\end{array}$ & Glass & Right & 120 Gy (mean) & 1 & $\begin{array}{c}139 \text { days } \\
\text { (mean) }\end{array}$ & $\begin{array}{l}20.3 \% \text { (mean), } \\
17.2 \% \text { (median) }\end{array}$ \\
\hline $\begin{array}{l}\text { Gaba } \\
\text { (overlap w/Vouche) }\end{array}$ & 2009 & 20 & $\begin{array}{l}\operatorname{HCC}[17] \\
\text { CCA [3] }\end{array}$ & Glass & Right & $\begin{array}{l}175 \text { Gy (mean), } \\
132 \text { Gy (median) }\end{array}$ & 1.7 & $\begin{array}{c}18 \text { months } \\
\text { (mean) }\end{array}$ & $40 \%$ (mean) \\
\hline Edeline $^{*}$ & 2013 & 34 & $\mathrm{HCC}$ & $\begin{array}{c}30 \text { glass, } \\
4 \text { resin }\end{array}$ & $\begin{array}{c}23 \text { right, } \\
11 \text { left }\end{array}$ & 122 Gy (median) & 1 & 3 months & $38 \%$ (mean) \\
\hline Fernandez-Ros* & 2014 & 83 & $\begin{array}{c}\text { HCC [52], } \\
\text { CCA [4], } \\
\text { mCRC [13], } \\
14 \text { [other] }\end{array}$ & Resin & $\begin{array}{c}66 \text { right, } \\
17 \text { left }\end{array}$ & $\mathrm{N} / \mathrm{A}$ & 1 & $>26$ weeks & $45 \%$ (mean) \\
\hline Garlipp* & 2013 & 26 & $\begin{array}{c}\text { Mixed } \\
\text { metastases }\end{array}$ & Resin & Right & $\begin{array}{c}\text { N/A [activity } 1.2 \\
\text { GBq (mean)] }\end{array}$ & 1 & 46 days & $\begin{array}{c}29 \% \text { (mean), } \\
25.3 \% \text { (median) }\end{array}$ \\
\hline Teo* & 2014 & 17 & $\mathrm{HCC}$ & Resin & Right & $\mathrm{N} / \mathrm{A}$ & 1 & $\begin{array}{l}5 \text { months } \\
\text { (median) }\end{array}$ & $34.2 \%$ (mean) \\
\hline $\begin{array}{l}\text { Gabr } \\
\text { (overlap w/Vouche) }\end{array}$ & 2018 & 20 & $\mathrm{HCC}$ & Glass & Right & 128 Gy (median) & 1.2 & Not reported & 23.3\% (median) \\
\hline
\end{tabular}

*, studies included in the systematic review by Teo et al. HCC, hepatocellular carcinoma; CCA, cholangiocarcinona; mCRC, metastatic colorectal cancer.

study from the same group which included 20 patients who underwent RL and 11 who underwent radiation segmentectomy was similarly promising (127).

\section{Conclusions}

PVE remains a proven, highly effective technique for induction of liver hypertrophy prior to operative intervention in patients who would otherwise not be surgical candidates, but is not universally effective.
Attempts to iterate on and improve the technique, although promising, remain unproven and, in some cases, may place patients at higher risk of adverse outcomes. Furthermore, stimulation of tumor growth following PVE remains a poorly understood but potentially catastrophic concern $(63,128-130)$. Inconsistencies in patient selection, technical approach, reporting standards, and outcome measures have severely limited comparisons between these techniques and leave the inexperienced interventionalist with many choices and no clear path forward. Direct comparative 
studies with histopathologic correlation will be needed for further elucidate the mechanisms underlying and outcomes produced by these techniques, and to be able to better offer patients a safe, effective, and individualized approach to hepatic regeneration.

\section{Acknowledgments}

Funding: None.

\section{Footnote}

Conflicts of Interest: All authors have completed the ICMJE uniform disclosure form (available at https://hbsn. amegroups.com/article/view/10.21037/hbsn.2019.09.10/coif). The authors have no conflicts of interest to declare.

Ethical Statement: The authors are accountable for all aspects of the work in ensuring that questions related to the accuracy or integrity of any part of the work are appropriately investigated and resolved.

Open Access Statement: This is an Open Access article distributed in accordance with the Creative Commons Attribution-NonCommercial-NoDerivs 4.0 International License (CC BY-NC-ND 4.0), which permits the noncommercial replication and distribution of the article with the strict proviso that no changes or edits are made and the original work is properly cited (including links to both the formal publication through the relevant DOI and the license). See: https://creativecommons.org/licenses/by-nc$\mathrm{nd} / 4.0 /$.

\section{References}

1. Shirabe K, Shimada M, Gion T, et al. Postoperative liver failure after major hepatic resection for hepatocellular carcinoma in the modern era with special reference to remnant liver volume. J Am Coll Surg 1999;188:304-9.

2. Black DM, Behrns KE. A scientist revisits the atrophyhypertrophy complex: hepatic apoptosis and regeneration. Surg Oncol Clin N Am 2002;11:849-64.

3. Koniaris LG, McKillop IH, Schwartz SI, et al. Liver regeneration. J Am Coll Surg 2003;197:634-59.

4. Kim RD, Kim JS, Watanabe G, et al. Liver regeneration and the atrophy-hypertrophy complex. Semin Intervent Radiol 2008;25:92-103.

5. Lory J, Schweizer W, Blumgart LH, et al. The pathology of the atrophy/hypertrophy complex (AHC) of the liver. A light microscopic and immunohistochemical study. Histol Histopathol 1994;9:541-54.

6. van Gulik TM, van den Esschert JW. James Cantlie's early messages for hepatic surgeons: how the concept of preoperative portal vein occlusion was defined. HPB (Oxford) 2010;12:81-3.

7. Rous P, Larimore LD. Relation of the Portal Blood to Liver Maintenance: A Demonstration of Liver Atrophy Conditional on Compensation. J Exp Med 1920;31:609-32.

8. Schalm L, Schulte MJ, Bax HR, et al. The regenerative power of the liver and its reserve capacity for excreting bile; their possible significance in surgical treatment of biliary obstruction. Lancet 1952;1:75-81.

9. Kinoshita H, Sakai K, Hirohashi K, et al. Preoperative portal vein embolization for hepatocellular carcinoma. World J Surg 1986;10:803-8.

10. Makuuchi M, Thai BL, Takayasu K, et al. Preoperative portal embolization to increase safety of major hepatectomy for hilar bile duct carcinoma: a preliminary report. Surgery 1990;107:521-7.

11. Aloia TA. Associating Liver Partition and Portal Vein Ligation for Staged Hepatectomy: Portal Vein Embolization Should Remain the Gold Standard. JAMA Surg 2015;150:927-8.

12. Guiu B, Chevallier P, Denys A, et al. Simultaneous transhepatic portal and hepatic vein embolization before major hepatectomy: the liver venous deprivation technique. Eur Radiol 2016;26:4259-67.

13. Gaba RC, Lewandowski RJ, Kulik LM, et al. Radiation lobectomy: preliminary findings of hepatic volumetric response to lobar yttrium-90 radioembolization. Ann Surg Oncol 2009;16:1587-96.

14. Michalopoulos GK, DeFrances MC. Liver regeneration. Science 1997;276:60-6.

15. Michalopoulos GK. Liver regeneration. J Cell Physiol 2007;213:286-300.

16. Nagino M, Nimura $Y$, Kamiya J, et al. Changes in hepatic lobe volume in biliary tract cancer patients after right portal vein embolization. Hepatology 1995;21:434-9.

17. Shimamura T, Nakajima Y, Une Y, et al. Efficacy and safety of preoperative percutaneous transhepatic portal embolization with absolute ethanol: a clinical study. Surgery 1997;121:135-41.

18. Yamanaka N, Okamoto E, Kawamura E, et al. Dynamics of normal and injured human liver regeneration after hepatectomy as assessed on the basis of computed tomography and liver function. Hepatology 1993;18:79-85. 
19. Hemming AW, Reed AI, Howard RJ, et al. Preoperative portal vein embolization for extended hepatectomy. Ann Surg 2003;237:686-91; discussion 691-3.

20. Goto Y, Nagino M, Nimura Y. Doppler estimation of portal blood flow after percutaneous transhepatic portal vein embolization. Ann Surg 1998;228:209-13.

21. Taub R. Liver regeneration: from myth to mechanism. Nat Rev Mol Cell Biol 2004;5:836-47.

22. Stolz DB, Mars WM, Petersen BE, et al. Growth factor signal transduction immediately after two-thirds partial hepatectomy in the rat. Cancer Res 1999;59:3954-60.

23. Olsen PS, Poulsen SS, Kirkegaard P. Adrenergic effects on secretion of epidermal growth factor from Brunner's glands. Gut 1985;26:920-7.

24. Starzl TE, Francavilla A, Porter KA, et al. The effect of splanchnic viscera removal upon canine liver regeneration. Surg Gynecol Obstet 1978;147:193-207.

25. Johnson TN, Tucker GT, Tanner MS, et al. Changes in liver volume from birth to adulthood: a meta-analysis. Liver Transpl 2005;11:1481-93.

26. Ribero D, Chun YS, Vauthey JN. Standardized liver volumetry for portal vein embolization. Semin Intervent Radiol 2008;25:104-9.

27. Vauthey JN, Abdalla EK, Doherty DA, et al. Body surface area and body weight predict total liver volume in Western adults. Liver Transpl 2002;8:233-40.

28. Ribero D, Amisano M, Bertuzzo F, et al. Measured versus estimated total liver volume to preoperatively assess the adequacy of the future liver remnant: which method should we use? Ann Surg 2013;258:801-6; discussion 806-7.

29. Leung U, Simpson AL, Araujo RL, et al. Remnant growth rate after portal vein embolization is a good early predictor of post-hepatectomy liver failure. J Am Coll Surg 2014;219:620-30.

30. Abdalla EK, Hicks ME, Vauthey JN. Portal vein embolization: rationale, technique and future prospects. $\mathrm{Br}$ J Surg 2001;88:165-75.

31. Kishi Y, Abdalla EK, Chun YS, et al. Three hundred and one consecutive extended right hepatectomies: evaluation of outcome based on systematic liver volumetry. Ann Surg 2009;250:540-8.

32. Ribero D, Abdalla EK, Madoff DC, et al. Portal vein embolization before major hepatectomy and its effects on regeneration, resectability and outcome. Br J Surg 2007;94:1386-94.

33. Azoulay D, Castaing D, Krissat J, et al. Percutaneous portal vein embolization increases the feasibility and safety of major liver resection for hepatocellular carcinoma in injured liver. Ann Surg 2000;232:665-72.

34. Adam R, Pascal G, Castaing D, et al. Tumor progression while on chemotherapy: a contraindication to liver resection for multiple colorectal metastases? Ann Surg 2004;240:1052-61; discussion 1061-4.

35. Farges O, Belghiti J, Kianmanesh R, et al. Portal vein embolization before right hepatectomy: prospective clinical trial. Ann Surg 2003;237:208-17.

36. Shindoh J, Tzeng CW, Aloia TA, et al. Optimal future liver remnant in patients treated with extensive preoperative chemotherapy for colorectal liver metastases. Ann Surg Oncol 2013;20:2493-500.

37. Shindoh J, Truty MJ, Aloia TA, et al. Kinetic growth rate after portal vein embolization predicts posthepatectomy outcomes: toward zero liver-related mortality in patients with colorectal liver metastases and small future liver remnant. J Am Coll Surg 2013;216:201-9.

38. Makuuchi M, Kosuge T, Lygidakis NJ. New possibilities for major liver surgery in patients with Klatskin tumors or primary hepatocellular carcinoma--an old problem revisited. Hepatogastroenterology 1991;38:329-36.

39. Sugawara Y, Yamamoto J, Higashi H, et al. Preoperative portal embolization in patients with hepatocellular carcinoma. World J Surg 2002;26:105-10.

40. Nanashima A, Yamaguchi H, Shibasaki S, et al. Relationship between CT volumetry and functional liver volume using technetium-99m galactosyl serum albumin scintigraphy in patients undergoing preoperative portal vein embolization before major hepatectomy: a preliminary study. Dig Dis Sci 2006;51:1190-5.

41. de Graaf W, Bennink RJ, Vetelainen R, et al. Nuclear imaging techniques for the assessment of hepatic function in liver surgery and transplantation. J Nucl Med 2010;51:742-52.

42. Olthof PB, Coelen RJS, Bennink RJ, et al. (99m)Tcmebrofenin hepatobiliary scintigraphy predicts liver failure following major liver resection for perihilar cholangiocarcinoma. HPB (Oxford) 2017;19:850-8.

43. de Graaf W, van Lienden KP, van Gulik TM, et al. (99m)Tc-mebrofenin hepatobiliary scintigraphy with SPECT for the assessment of hepatic function and liver functional volume before partial hepatectomy. J Nucl Med 2010;51:229-36.

44. Kaibori M, Ha-Kawa SK, Maehara M, et al. Usefulness of Tc-99m-GSA scintigraphy for liver surgery. Ann Nucl Med 2011;25:593-602.

45. Kato A, Nakamoto Y, Ishimori T, et al. Predictability of (99m)Tc-Galactosyl Human Serum Albumin Scintigraphy 
for Posthepatectomy Liver Failure. AJR Am J Roentgenol 2018;210:158-65.

46. Tajima T, Takao H, Akai H, et al. Relationship between liver function and liver signal intensity in hepatobiliary phase of gadolinium ethoxybenzyl diethylenetriamine pentaacetic acid-enhanced magnetic resonance imaging. J Comput Assist Tomogr 2010;34:362-6.

47. Kamimura K, Fukukura Y, Yoneyama T, et al. Quantitative evaluation of liver function with $\mathrm{T} 1$ relaxation time index on Gd-EOB-DTPA-enhanced MRI: comparison with signal intensity-based indices. J Magn Reson Imaging 2014;40:884-9.

48. Ninomiya M, Shirabe K, Kayashima H, et al. Functional assessment of the liver with gadolinium-ethoxybenzyldiethylenetriamine penta-acetate-enhanced MRI in livingdonor liver transplantation. Br J Surg 2015;102:944-51.

49. Denys AL, Abehsera M, Sauvanet A, et al. Failure of right portal vein ligation to induce left lobe hypertrophy due to intrahepatic portoportal collaterals: successful treatment with portal vein embolization. AJR Am J Roentgenol 1999;173:633-5.

50. Nagino M, Nimura Y, Kamiya J, et al. Selective percutaneous transhepatic embolization of the portal vein in preparation for extensive liver resection: the ipsilateral approach. Radiology 1996;200:559-63.

51. Madoff DC, Abdalla EK, Gupta S, et al. Transhepatic ipsilateral right portal vein embolization extended to segment IV: improving hypertrophy and resection outcomes with spherical particles and coils. J Vasc Interv Radiol 2005;16:215-25.

52. Li D, Madoff DC. Portal vein embolization for induction of selective hepatic hypertrophy prior to major hepatectomy: rationale, techniques, outcomes and future directions. Cancer Biol Med 2016;13:426-42.

53. Di Stefano DR, de Baere T, Denys A, et al. Preoperative percutaneous portal vein embolization: evaluation of adverse events in 188 patients. Radiology 2005;234:625-30.

54. Kodama Y, Shimizu T, Endo H, et al. Complications of percutaneous transhepatic portal vein embolization. J Vasc Interv Radiol 2002;13:1233-7.

55. Madoff DC. Portal vein embolization: the continued search for the ideal embolic agent. J Vasc Interv Radiol 2014;25:1053-5.

56. Fischman AM, Ward TJ, Horn JC, et al. Portal vein embolization before right hepatectomy or extended right hepatectomy using sodium tetradecyl sulfate foam: technique and initial results. J Vasc Interv Radiol 2014;25:1045-53.
57. Bent CL, Low D, Matson MB, et al. Portal vein embolization using a nitinol plug (Amplatzer vascular plug) in combination with histoacryl glue and iodinized oil: adequate hypertrophy with a reduced risk of nontarget embolization. Cardiovasc Intervent Radiol 2009;32:471-7.

58. Guiu B, Bize P, Gunthern D, et al. Portal vein embolization before right hepatectomy: improved results using n-butyl-cyanoacrylate compared to microparticles plus coils. Cardiovasc Intervent Radiol 2013;36:1306-12.

59. Abulkhir A, Limongelli P, Healey AJ, et al. Preoperative portal vein embolization for major liver resection: a metaanalysis. Ann Surg 2008;247:49-57.

60. Wajswol E, Jazmati T, Contractor S, et al. Portal Vein Embolization Utilizing N-Butyl Cyanoacrylate for Contralateral Lobe Hypertrophy Prior to Liver Resection: A Systematic Review and Meta-Analysis. Cardiovasc Intervent Radiol 2018;41:1302-12.

61. Isfordink CJ, Samim M, Braat M, et al. Portal vein ligation versus portal vein embolization for induction of hypertrophy of the future liver remnant: A systematic review and meta-analysis. Surg Oncol 2017;26:257-67.

62. van Lienden KP, van den Esschert JW, de Graaf W, et al. Portal vein embolization before liver resection: a systematic review. Cardiovasc Intervent Radiol 2013;36:25-34.

63. Pamecha V, Levene A, Grillo F, et al. Effect of portal vein embolisation on the growth rate of colorectal liver metastases. Br J Cancer 2009; 100:617-22.

64. Hoekstra LT, van Lienden KP, Doets A, et al. Tumor progression after preoperative portal vein embolization. Ann Surg 2012;256:812-7; discussion 817-8.

65. Schnitzbauer AA, Lang SA, Goessmann H, et al. Right portal vein ligation combined with in situ splitting induces rapid left lateral liver lobe hypertrophy enabling 2-staged extended right hepatic resection in small-for-size settings. Ann Surg 2012;255:405-14.

66. Schadde E, Ardiles V, Robles-Campos R, et al. Early survival and safety of ALPPS: first report of the International ALPPS Registry. Ann Surg 2014;260:829-36; discussion 836-8.

67. Sandstrom P, Rosok BI, Sparrelid E, et al. ALPPS Improves Resectability Compared With Conventional Two-stage Hepatectomy in Patients With Advanced Colorectal Liver Metastasis: Results From a Scandinavian Multicenter Randomized Controlled Trial (LIGRO Trial). Ann Surg 2018;267:833-40.

68. Eshmuminov D, Raptis DA, Linecker M, et al. Metaanalysis of associating liver partition with portal 
vein ligation and portal vein occlusion for two-stage hepatectomy. Br J Surg 2016;103:1768-82.

69. Knoefel WT, Gabor I, Rehders A, et al. In situ liver transection with portal vein ligation for rapid growth of the future liver remnant in two-stage liver resection. Br J Surg 2013;100:388-94.

70. Nadalin S, Capobianco I, Li J, et al. Indications and limits for associating liver partition and portal vein ligation for staged hepatectomy (ALPPS). Lessons Learned from 15 cases at a single centre. Z Gastroenterol 2014;52:35-42.

71. Moris D, Ronnekleiv-Kelly S, Kostakis ID, et al. Operative Results and Oncologic Outcomes of Associating Liver Partition and Portal Vein Ligation for Staged Hepatectomy (ALPPS) Versus Two-Stage Hepatectomy (TSH) in Patients with Unresectable Colorectal Liver Metastases: A Systematic Review and Meta-Analysis. World J Surg 2018;42:806-15.

72. Schadde E, Raptis DA, Schnitzbauer AA, et al. Prediction of Mortality After ALPPS Stage-1: An Analysis of 320 Patients From the International ALPPS Registry. Ann Surg 2015;262:780-5; discussion 785-6.

73. Kang D, Schadde E. Hypertrophy and Liver Function in ALPPS: Correlation with Morbidity and Mortality. Visc Med 2017;33:426-33.

74. Gall TM, Sodergren MH, Frampton AE, et al. Radiofrequency-assisted Liver Partition with Portal vein ligation (RALPP) for liver regeneration. Ann Surg 2015;261:e45-6.

75. Matsuo K, Hiroshima Y, Yamazaki K, et al. Immaturity of Bile Canalicular-Ductule Networks in the Future Liver Remnant While Associating Liver Partition and Portal Vein Occlusion for Staged Hepatectomy (ALPPS). Ann Surg Oncol 2017;24:2456-64.

76. Matsuo K, Murakami T, Kawaguchi D, et al. Histologic features after surgery associating liver partition and portal vein ligation for staged hepatectomy versus those after hepatectomy with portal vein embolization. Surgery 2016;159:1289-98.

77. Schadde E, Schnitzbauer AA, Tschuor C, et al. Systematic review and meta-analysis of feasibility, safety, and efficacy of a novel procedure: associating liver partition and portal vein ligation for staged hepatectomy. Ann Surg Oncol 2015;22:3109-20.

78. Alvarez FA, Ardiles V, Sanchez Claria R, et al. Associating liver partition and portal vein ligation for staged hepatectomy (ALPPS): tips and tricks. J Gastrointest Surg 2013;17:814-21

79. Robles R, Parrilla P, Lopez-Conesa A, et al. Tourniquet modification of the associating liver partition and portal ligation for staged hepatectomy procedure. Br J Surg 2014;101:1129-34; discussion 1134.

80. Li J, Kantas A, Ittrich H, et al. Avoid "All-Touch" by Hybrid ALPPS to Achieve Oncological Efficacy. Ann Surg 2016;263:e6-7.

81. de Santibanes E, Alvarez FA, Ardiles V, et al. Inverting the ALPPS paradigm by minimizing first stage impact: the Mini-ALPPS technique. Langenbecks Arch Surg 2016;401:557-63.

82. Belghiti J, Dokmak S, Schadde E. ALPPS: Innovation for innovation's sake. Surgery 2016;159:1287-8.

83. Tanaka K, Matsuo K, Murakami T, et al. Associating liver partition and portal vein ligation for staged hepatectomy (ALPPS): short-term outcome, functional changes in the future liver remnant, and tumor growth activity. Eur J Surg Oncol 2015;41:506-12.

84. Yamakado K, Takeda K, Matsumura K, et al. Regeneration of the un-embolized liver parenchyma following portal vein embolization. J Hepatol 1997;27:871-80.

85. Gruttadauria S, Luca A, Mandala L, et al. Sequential preoperative ipsilateral portal and arterial embolization in patients with colorectal liver metastases. World J Surg 2006;30:576-8.

86. Imamura H, Seyama Y, Makuuchi M, et al. Sequential transcatheter arterial chemoembolization and portal vein embolization for hepatocellular carcinoma: the university of Tokyo experience. Semin Intervent Radiol 2008;25:146-54.

87. Nakao N, Miura K, Takahashi H, et al. Hepatocellular carcinoma: combined hepatic, arterial, and portal venous embolization. Radiology 1986;161:303-7.

88. Yamakado K, Hirano T, Kato N, et al. Hepatocellular carcinoma: treatment with a combination of transcatheter arterial chemoembolization and transportal ethanol injection. Radiology 1994;193:75-80.

89. Yamakado K, Nakatsuka A, Tanaka N, et al. Long-term follow-up arterial chemoembolization combined with transportal ethanol injection used to treat hepatocellular carcinoma. J Vasc Interv Radiol 1999;10:641-7.

90. Aoki T, Imamura H, Hasegawa K, et al. Sequential preoperative arterial and portal venous embolizations in patients with hepatocellular carcinoma. Arch Surg 2004;139:766-74.

91. Ogata S, Belghiti J, Farges O, et al. Sequential arterial and portal vein embolizations before right hepatectomy in patients with cirrhosis and hepatocellular carcinoma. Br J Surg 2006;93:1091-8.

92. de Graaf W, van den Esschert JW, van Lienden KP, et 
al. Induction of tumor growth after preoperative portal vein embolization: is it a real problem? Ann Surg Oncol 2009; 16:423-30.

93. Simoneau E, Aljiffry M, Salman A, et al. Portal vein embolization stimulates tumour growth in patients with colorectal cancer liver metastases. HPB (Oxford) 2012;14:461-8.

94. Gruttadauria S, Gridelli B. Sequential preoperative ipsilateral portal and arterial embolization in patients with liver tumors: is it really the best approach? World J Surg 2007;31:2427-8.

95. Yoo H, Kim JH, Ko GY, et al. Sequential transcatheter arterial chemoembolization and portal vein embolization versus portal vein embolization only before major hepatectomy for patients with hepatocellular carcinoma. Ann Surg Oncol 2011;18:1251-7.

96. Vilgrain V, Sibert A, Zappa M, et al. Sequential arterial and portal vein embolization in patients with cirrhosis and hepatocellular carcinoma: the hospital beaujon experience. Semin Intervent Radiol 2008;25:155-61.

97. Peng PD, Hyder O, Bloomston M, et al. Sequential intraarterial therapy and portal vein embolization is feasible and safe in patients with advanced hepatic malignancies. HPB (Oxford) 2012;14:523-31.

98. Nagino M, Kanai M, Morioka A, et al. Portal and arterial embolization before extensive liver resection in patients with markedly poor functional reserve. J Vasc Interv Radiol 2000;11:1063-8.

99. Wallace MJ, Ahrar K, Madoff DC. Chemoembolization of the liver after portal vein embolization: report of three cases. J Vasc Interv Radiol 2008;19:1513-7.

100. Kang BK, Kim JH, Kim KM, et al. Transcatheter arterial chemoembolization for hepatocellular carcinoma after attempted portal vein embolization in 25 patients. AJR Am J Roentgenol 2009;193:W446-51.

101. Ko GY, Hwang S, Sung KB, et al. Interventional oncology: new options for interstitial treatments and intravascular approaches: right hepatic vein embolization after right portal vein embolization for inducing hypertrophy of the future liver remnant. J Hepatobiliary Pancreat Sci 2010;17:410-2.

102. Hwang S, Lee SG, Ko GY, et al. Sequential preoperative ipsilateral hepatic vein embolization after portal vein embolization to induce further liver regeneration in patients with hepatobiliary malignancy. Ann Surg 2009;249:608-16.

103. Hwang S, Lee SG, Park KM, et al. Hepatic venous congestion in living donor liver transplantation: preoperative quantitative prediction and follow-up using computed tomography. Liver Transpl 2004;10:763-70.

104.Munene G, Parker RD, Larrigan J, et al. Sequential preoperative hepatic vein embolization after portal vein embolization for extended left hepatectomy in colorectal liver metastases. World J Surg Oncol 2013;11:134.

105. Balzan SM, Gava VG, Magalhaes MA, et al. Outflow modulation to target liver regeneration: something old, something new. Eur J Surg Oncol 2014;40:140-3.

106. Sano K, Makuuchi M, Miki K, et al. Evaluation of hepatic venous congestion: proposed indication criteria for hepatic vein reconstruction. Ann Surg 2002;236:241-7.

107. Guiu B, Quenet F, Escal L, et al. Extended liver venous deprivation before major hepatectomy induces marked and very rapid increase in future liver remnant function. Eur Radiol 2017;27:3343-52.

108. Le Roy B, Perrey A, Fontarensky M, et al. Combined Preoperative Portal and Hepatic Vein Embolization (Biembolization) to Improve Liver Regeneration Before Major Liver Resection: A Preliminary Report. World J Surg 2017;41:1848-56.

109. Hocquelet A, Sotiriadis C, Duran R, et al. Preoperative Portal Vein Embolization Alone with Biliary Drainage Compared to a Combination of Simultaneous Portal Vein, Right Hepatic Vein Embolization and Biliary Drainage in Klatskin Tumor. Cardiovasc Intervent Radiol 2018;41:1885-91.

110. Deshayes E, Schadde E, Piron L, et al. Extended Liver Venous Deprivation Leads to a Higher Increase in Liver Function that ALPPS in Early Assessment : A comment to "Sparrelid, E. et al. Dynamic Evaluation of Liver Volume and Function in Associating Liver Partition and Portal Vein Ligation for Staged Hepatectomy. Journal of Gastrointestinal Surgery (2017)". J Gastrointest Surg 2017;21:1754-5.

111. Sparrelid E, Jonas E, Tzortzakakis A, et al. Dynamic Evaluation of Liver Volume and Function in Associating Liver Partition and Portal Vein Ligation for Staged Hepatectomy. J Gastrointest Surg 2017;21:967-74.

112.Jakobs TF, Saleem S, Atassi B, et al. Fibrosis, portal hypertension, and hepatic volume changes induced by intra-arterial radiotherapy with $90 y$ ttrium microspheres. Dig Dis Sci 2008;53:2556-63.

113. Gulec SA, Pennington K, Hall M, et al. Preoperative Y-90 microsphere selective internal radiation treatment for tumor downsizing and future liver remnant recruitment: a novel approach to improving the safety of major hepatic resections. World J Surg Oncol 2009;7:6. 
114. Siddiqi NH, Devlin PM. Radiation lobectomy-a minimally invasive treatment model for liver cancer: case report. J Vasc Interv Radiol 2009;20:664-9.

115. Malhotra A, Liu DM, Talenfeld AD. Radiation Segmentectomy and Radiation Lobectomy: A Practical Review of Techniques. Tech Vasc Interv Radiol 2019;22:49-57.

116. Vouche M, Lewandowski RJ, Atassi R, et al. Radiation lobectomy: time-dependent analysis of future liver remnant volume in unresectable liver cancer as a bridge to resection. J Hepatol 2013;59:1029-36.

117. Teo JY, Allen JC Jr, Ng DC, et al. A systematic review of contralateral liver lobe hypertrophy after unilobar selective internal radiation therapy with Y90. HPB (Oxford) 2015. [Epub ahead of print].

118. Ahmadzadehfar H, Meyer C, Ezziddin S, et al. Hepatic volume changes induced by radioembolization with $90 \mathrm{Y}$ resin microspheres. A single-centre study. Eur J Nucl Med Mol Imaging 2013;40:80-90.

119.Edeline J, Lenoir L, Boudjema K, et al. Volumetric changes after (90)y radioembolization for hepatocellular carcinoma in cirrhosis: an option to portal vein embolization in a preoperative setting? Ann Surg Oncol 2013;20:2518-25.

120. Theysohn JM, Ertle J, Muller S, et al. Hepatic volume changes after lobar selective internal radiation therapy (SIRT) of hepatocellular carcinoma. Clin Radiol 2014;69:172-8.

121.Fernandez-Ros N, Silva N, Bilbao JI, et al. Partial liver volume radioembolization induces hypertrophy in the spared hemiliver and no major signs of portal hypertension. HPB (Oxford) 2014;16:243-9.

122. Garlipp B, de Baere T, Damm R, et al. Left-liver hypertrophy after therapeutic right-liver radioembolization is substantial but less than after portal vein embolization. Hepatology 2014;59:1864-73.

123. Teo JY, Goh BK, Cheah FK, et al. Underlying liver disease influences volumetric changes in the spared hemiliver after selective internal radiation therapy with $90 \mathrm{Y}$ in patients with hepatocellular carcinoma. J Dig Dis 2014;15:444-50.

124.Palard X, Edeline J, Rolland Y, et al. Dosimetric parameters predicting contralateral liver hypertrophy after unilobar radioembolization of hepatocellular carcinoma. Eur J Nucl Med Mol Imaging 2018;45:392-401.

125. Goebel J, Sulke M, Lazik-Palm A, et al. Factors associated with contralateral liver hypertrophy after unilateral radioembolization for hepatocellular carcinoma. PLoS One 2017;12:e0181488.

126.Lewandowski RJ, Donahue L, Chokechanachaisakul A, et al. (90) Y radiation lobectomy: Outcomes following surgical resection in patients with hepatic tumors and small future liver remnant volumes. J Surg Oncol 2016;114:99-105.

127. Gabr A, Abouchaleh N, Ali R, et al. Outcomes of Surgical Resection after Radioembolization for Hepatocellular Carcinoma. J Vasc Interv Radiol 2018;29:1502-10 e1.

128. Elias D, De Baere T, Roche A, et al. During liver regeneration following right portal embolization the growth rate of liver metastases is more rapid than that of the liver parenchyma. Br J Surg 1999;86:784-8.

129. Hayashi S, Baba Y, Ueno K, et al. Acceleration of primary liver tumor growth rate in embolized hepatic lobe after portal vein embolization. Acta Radiol 2007;48:721-7.

130. Kokudo N, Tada K, Seki M, et al. Proliferative activity of intrahepatic colorectal metastases after preoperative hemihepatic portal vein embolization. Hepatology 2001;34:267-72.

Cite this article as: Kim D, Cornman-Homonoff J, Madoff DC. Preparing for liver surgery with "Alphabet Soup": PVE, ALPPS, TAE-PVE, LVD and RL. HepatoBiliary Surg Nutr 2020;9(2):136-151. doi: 10.21037/hbsn.2019.09.10 